\title{
The disability self-direction movement: Considering the benefits and challenges for an Australian response
}

Michelle Crozier, Heidi Muenchberger, Jacinta Colley and Carolyn Ehrlich

\begin{abstract}
The following article provides a snapshot of the current self-direction movement within the disability sector across the industrialised world, with particular emphasis on the Australian context. As a global movement, self-direction has been in progress for several decades through a variety of implemented responses. Despite implementation variation, all self-direction models aim to facilitate individual control and decision making in care and support services. We describe self-direction, its various models and programs, and explore its benefits and challenges. We conclude by making broad recommendations for decision makers involved in self-direction. In particular, we offer a hierarchical decision tree that can be used to inform policy decisions at a systems - government policy - and organisational level.
\end{abstract}

Keywords: Self-directed, consumer-directed, disability, individualised funding, person-centred 


\section{Introduction}

The disability sector in Australia is currently undergoing significant change that places increasing importance on the individual and their right to greater service choice and control, and to undertake self-directed care. These changes have been occurring at a policy level in most Australian state jurisdictions for many years but have assumed greater relevance in light of the recent findings from the Productivity Commission outlining the need for structural reform to address inequalities, inefficiencies, and a lack of funding in the disability sector (Productivity Commission 2011). State-based policies and frameworks such as Queensland's 'Your Life Your Choice: Self-directed support framework' (The State of Queensland 2012) and 'Stronger Together' in New South Wales (New South Wales Government 2010) reflect this movement towards self-direction, as does the Federal Government's commitment to a National Disability Insurance Scheme in 2012.

In this article, self-direction refers to a range of terms including consumer-directed care/support, and individualised funding. Put simply, self-direction aims to empower individuals by providing them with more choice and control (Barczyk \& Lincove 2010). Four key components of self-directed support include participant control, participant responsibility, participant choice, and avoidance of conflict of interest (Cook et al. 2010). In the context of disability support, this translates to enabling people - and family or friends - to participate actively in goal setting, planning, selecting and purchasing support services that suit their individual preferences and situations (The State of Queensland 2012).

Over the last century, models of disability care have moved from religious to medical ideology, and then rights-based approaches (Clapton \& Fitzgerald 1997). Self-direction as a paradigm for service delivery has its origins in the community living movement within the disability and mental health sector (de Miranda 2004). The community or independent living movement first emerged in the 1970s (Gloag 1985) as families and people with disabilities rejected large-scale institutional accommodation settings as the only response to their needs. As self-direction was traditionally a community-based and not a State-based response, any self-directed approach could be considered at risk of perversion by generic implementation by the State.

As all State jurisdictions in Australia have made overt commitment towards a self-direction policy, it was considered timely to review the current models of self-direction, the support services offered under self-direction, and its future application to proposed schemes in Australia. A systematic search of the literature was conducted to explore the existing research and knowledge on self-directed models of support from Australian and international studies with the aim of identifying important considerations for Australia in the development of models of self-directed support. Articles that were included in the review focused on consumer needs, experiences, and outcomes of self-directed support 
for minority or disadvantaged groups and their caregivers. Articles focusing on the American health insurance scheme, consumer training packages, skill development, and the medical context were excluded.

Three databases (ScienceDirect, Medline and CINAHL) were searched for peer-reviewed journal articles published between 2000 to 2012. A range of search terms were applied including combinations of 'client-led', 'consumer-direct"', 'self-direct"' and 'support', 'care' and 'service*'. The searches 'client-led care', 'consumer-directed care' and 'self-directed care' returned the most results and were therefore used as the key terms. The initial search identified 376 articles, with 340 remaining after duplicates were removed. Two authors independently reviewed the titles and abstracts of each article using the inclusion and exclusion criteria as outlined above. These selected titles were merged, resulting in 96 articles. Where an article had only been selected by one author, the inclusion and exclusion criteria were reapplied and discussion undertaken until consensus was achieved. This left 67 articles for full review. Two articles, the full text of which was unable to be sourced, were subsequently removed from the analysis. A total of 65 articles were read in full and the exclusion criteria applied, resulting in a total of 38 peer-reviewed articles for analysis. Additional papers and relevant grey literature were sourced from the reference lists of selected articles and included where they also met the selection criteria. This resulted in a total of 52 documents informing the final manuscript.

The following paper describes different models of self-direction that emerged from the literature as well as an analysis of the challenges and benefits of implementing a self-directed approach. The article concludes by offering a self-direction hierarchical decision-tree for use at system and organisational policy levels.

\section{Models of self-direction}

While the general aim of self-directed models of support is to provide consumers with greater choice and control, self-directed support initiatives can vary in the level of independence, choice and control that they offer (Cook et al. 2010; Kim et al. 2006; Low et al. 2012). Programs also differ in the amount of support delivered from service providers in terms of service coordination, organisational management, and financial administration. While models of self-directed support would ideally allow for people to decide how much control they would like over their support, the literature and reports of existing programs and strategies identify three broad categories of approaches; (1) the traditional agency-directed approach, which involves no self-direction; (2) a combination of case management and self-direction; and (3) an entirely consumer-directed approach (Adelman et al. 2012; Kim et al. 2006; Kodner 2003; Putnam et al. 2010).

This most flexible of the self-directed models is sometimes described as an 'open' model in which consumers are given a cash payment and complete discretion over how to spend this (Alakeson 2010). In this model, support funds do not have to be acquitted; however, reviews are conducted to ensure adequate, 
suitable support is being received. Alternatively, in the second model, referred to as the 'budget' or 'planned' model, individual budgets are calculated based on a selected formula. Consumers then go through the process of identifying their needs and goals and select goods and services to suit their individual requirements without exceeding their given budget. This model of self-directed support has more restrictions and is more closely monitored, as care plans are generally required to be approved by an agency or case manager and consumers must record and account for their purchases.

In order to relieve consumers of the additional administrative responsibilities that follow greater choice and control through a self-directed model, such as employing support workers, financial management services - payroll agents, employer agents, and fiscal intermediary organisations - are often used for the financial responsibilities associated with managing support services (Scherzer et al. 2007). Some agencies take responsibility for the role of administering and accounting for funds on behalf of people. Other programs, such as those found in the United States, seek to overcome issues of undue influence by clearly specifying that an agency cannot be involved in financial management for self-directed programs if that agency is involved in service delivery (Cook et al. 2010). Three basic approaches to fiscal management in self-directed programs are articulated by Scherzer and colleagues (2007): (1) fiscal/employment agent; (2) agency with choice; and (3) public authority. These fiscal management approaches differ in terms of the tasks that the consumer and the service take on, and who is considered to be the employer of the worker under common law.

Other authors (for example, Lombe et al. 2009) discuss the notion of capacity building in relation to people with a disability who undertake self-direction. The Credit Union model is one capacity building model that has been used in trials of the Cash and Counselling program in the United States. This model is able to provide fiscal tasks such as deposits, tracking, distribution, payroll and invoice payment as well as providing training services (Lombe et al. 2009). In another example of fiscal intermediary involvement, one self-directed program created in a public-academic partnership involved a university assuming the role of billing and withholding money for payroll taxes (Cook et al. 2010).

\section{Self-directed support programs}

A number of countries around the world including Austria, Germany, the Netherlands, New Zealand, the United Kingdom and the United States have trialled and implemented self-directed support programs (Alakeson 2010; Kodner 2003). The models of self-direction employed vary in the control and flexibility offered to consumers, and are subject to ongoing studies and evaluations in order to make adjustments to the programs to ensure their effectiveness and efficiency. Two international programs often discussed in the literature include the Cash and Counselling program (mentioned above) from the United States and the Individual Budgets program in the United Kingdom. 
The Cash and Counselling program is a particularly flexible program running in the United States (Sciegaj et al. 2004). The program allowed Medicaid recipients in participating States to manage a monthly cash allowance, equivalent to the expenditure directed towards their support in a traditional agency-directed system (Loughlin et al. 2004; Mahoney et al. 2002; Shen, Smyer, Mahoney, Simon-Rusinowitz et al. 2008). In this program money could be used to hire a support worker, purchase goods or services, or make home renovations which supported the recipient's needs (Shen, Smyer, Mahoney, Simon-Rusinowitz et al. 2008). Consumers were also allocated a consultant - also referred to as a 'counsellor' - whose role was to provide advice and assistance rather than making recommendations or making decisions for the consumer (Doty et al. 2010). Evaluations of the program showed that the majority of participants in the program used their allowance to hire workers for assistance with personal care, routine health care needs such as taking medication, housework, and transportation assistance (Barczyk \& Lincove 2010; Lombe et al. 2009). In a study comparing consumers involved in the program with those receiving traditional assistance from Medicaid it was revealed that consumers given control over their own budgets reported greater satisfaction with support arrangements and fewer unmet needs. Involvement in the program also appeared to have a positive impact on reported personal care and wellbeing (Shen, Smyer, Mahoney, Simon-Rusinowitz et al. 2008). This program and subsequent self-directed initiatives are believed to be appropriate for a range of people including: elderly consumers; non-elderly adults; children, with representatives (Carlson et al. 2007); people with mental health problems (Alakeson 2007; Shen, Smyer, Mahoney, Loughlin et al. 2008; Shen, Smyer, Mahoney, Simon-Rusinowitz et al. 2008); and people with physical disabilities (Barczyk \& Lincove 2010).

A similarly flexible program was also implemented in the United Kingdom (Low et al. 2012). The Individual Budgets Program allowed participants to decide how they would receive their allowance, with options including direct payments, payments into joint accounts, or having a local authority manage the money. Consumers were supported in the planning and use of their budgets and a senior manager in the program was required to assess and approve the plan before money could be spent. Evaluations of this program revealed differences in outcomes for consumers within each group (Glendinning et al. 2008). Consumers in the program with mental health problems reported higher quality of life compared to those not involved in the program. Adults with physical disabilities reported greater satisfaction with their support and higher quality of support compared to those receiving traditional services, and people with learning disabilities were more likely to report that they felt in charge of their lives compared to the control group. Interestingly, older adults managing their own budgets reported lower psychological wellbeing than those in the control group, a finding which is suspected to be due to the increased burden felt by those in charge of planning and organising their own support (Glendinning et al. 2008). 
In Australia, models of self-directed support have been in use since at least 1998 (Department of Health and Ageing 2012). However, there is limited peer-reviewed literature that reports on the structure or outcomes of existing self-directed programs (Crozier \& Muenchberger 2013). Recently, the Department of Health and Ageing introduced a pilot program for self-directed support for elderly people (Department of Health and Ageing 2012). In 2010, 500 self-directed support packages were available to eligible participants who requested to be involved with the program. Consumers were able to decide on the services received and the people hired as support workers; however, service providers retained responsibility for maintaining the quality of the services, for example, conducting background checks on employees, managing the budget and bookkeeping (Low et al. 2012). The main types of support used by participants in the program included assistance with daily activities such as domestic assistance, social support, nutrition, hydration, and meal preparation and nursing care (Department of Health and Ageing 2012). Results from the initial pilot program found no differences on a measure of wellbeing specifically relating to adverse events/health outcomes between the participants in the self-directed support program and a comparison group receiving standard support packages. However, participants - particularly those with high support needs such as dementia - reported an increase in satisfaction with their ability to participate in social and community activities, their social relationships, and their health and wellbeing (Low et al. 2012).

A self-directed support program for families with disabled children was also implemented in Melbourne, Australia (Ottmann et al. 2009; Ottmann \& Laragy 2010). Families were given a budget to spend on goods and services related to support needs and were able to choose a service provider from an approved list (Ottman et al. 2009). Although many had experience in managing support packages, most families chose not to take on the additional administrative responsibilities, instead deciding to pay a fee to the host organisation for providing this service. Research assessing the program was conducted using a longitudinal design, thereby providing insight into some of the longer-term issues associated with self-directed care. There were reported benefits to both the children and their caregivers in quality of life and support received, particularly in terms of flexibility and variety of the programs undertaken - for instance, gourmet cooking classes - and flexibility to choose their own staff and determine when they provided support. However, caregivers also reported feeling increasingly isolated over time, highlighting the importance of ensuring ongoing support and specific skills training/competency development to maintain satisfaction and the ability to cope with the added responsibilities of managing support packages over time.

\section{Benefits of self-directed support}

Research conducted on existing self-directed models of support and self-directed support programs identify a number of benefits of adopting models which allow greater consumer choice and control. Self-directed models represent 
a more respectful approach to assisting people with disabilities, aiming to empower consumers by focusing on their strengths, goals and abilities rather than focusing on illness or disability (Barczyk \& Lincove 2010; Duffy 2007a). It also facilitates consumers to develop a sense of control (Barczyk \& Lincove 2010) and the opportunity for greater self-determination, which has consistently been linked to improved quality of life (Lachapelle et al. 2005; McDougall et al. 2010; Wehmeyer \& Schwartz 1998). Although self-direction may not be the desired course of action for many people with a disability, it will certainly be a choice for some Australians with a disability under the National Disability Insurance Scheme.

The shift towards self-directed models of support also reflects the desire for greater independence from community-based services, and consequently recipients' control over their lives, as reported by a number of consumers (Barczyk \& Lincove 2010; Mahoney et al. 2002; Mahoney et al. 2004). Research indicates that both consumers and their caregivers, including carers of children with disabilities, are interested in having more input into the decision-making process and coordination of day-to-day services (Loughlin et al. 2004; Putnam et al. 2010). Unsurprisingly, self-directed support is of particular interest to those who are dissatisfied with the services they are currently receiving, or who believe that their needs are only partially being met (Department of Health and Ageing 2012, Loughlin et al. 2004, Mahoney et al. 2002). There are some reports that elderly people are less likely to be interested in directing their own services than younger people. Also, preferences vary among age groups in relation to the preferred model of support and the degree to which they would like control over their support (Adams \& Drake 2006; Sciegaj et al. 2004) or the support of the person they are caring for (Putnam et al. 2010). Overall, consumers have indicated a strong preference for self-directed models of support (Gray et al. 2009; Grossman et al. 2007) and regardless of the level of control preferred, individuals believe that they should be able to choose the model of service provision and level of independence for their care (Putnam et al. 2010).

Consumers also report high levels of satisfaction with self-directed services (Cook et al. 2008; Kim et al. 2006; Young \& Sikma 2003).

Increased satisfaction with support have been reported after changing from agency-directed services to self-directed models of support (Alakeson 2008; 2010; Gray et al. 2009; Shen, Smyer, Mahoney, Simon-Rusinowitz et al. 2008). Additionally, comparisons of consumers directing their own services and those receiving agency-directed services demonstrate that those involved in self-directed programs report greater satisfaction with the availability and type of services they received (Carlson et al. 2007; Cook et al. 2008), as well as progress towards their personal goals (Cook et al. 2008), and were more likely to feel that their needs were being met (Alakeson 2007). Cultural issues also play a role in consumer satisfaction with self-directed programs, as increased flexibility and choice and control over support workers is identified as important by people from culturally and linguistically diverse backgrounds (Barczyk \& Lincove 2010; Department of Health and Ageing 2012). 
Self-direction also appears to have resulted in increased access to quality services for many consumers (Alakeson 2010). Hiring family and friends as carers resulted in an increased number of hours of services received, with participants receiving the full number of hours of personal care allocated, whereas consumers receiving traditional services often do not use all of the hours allocated due to difficulty finding staff (Alakeson 2010). The support provided under self-directed models has been found to be the same quality as support provided under agency-directed models, despite the reduced ability of agencies to monitor the support and ensure that it remains of a high quality (Gray et al. 2009; Kim et al. 2006; Young \& Sikma 2003). Some reports have indicated more positive health outcomes resulting from self-directed models (Cook et al. 2008; Shen, Smyer, Mahoney, Loughlin et al. 2008), including fewer unmet needs compared to consumers receiving agency-directed services (Carlson et al. 2007). These identified benefits of self-directed supported are summarised alongside with the challenges in Table 1.

Table 1. Summary of benefits and challenges associated with self-directed models

\begin{tabular}{|c|c|}
\hline Benefits & Challenges \\
\hline Empower consumers & Ability to manage funds \\
\hline Focus on strengths, goals and abilities & Inappropriate use of allowance \\
\hline Develop a sense of control & Inadequate services \\
\hline $\begin{array}{l}\text { Greater self-determination linked to improved } \\
\text { quality of life }\end{array}$ & $\begin{array}{l}\text { Participant variation in terms of their interest in } \\
\text { managing the support received }\end{array}$ \\
\hline Greater control over life & Changes regarding amount of control desired \\
\hline $\begin{array}{l}\text { Fulfilment of desire to have more input into service } \\
\text { decision-making and coordination }\end{array}$ & Intended or unintended exploitation \\
\hline High levels of satisfaction & $\begin{array}{l}\text { Transition challenges for agencies and professionals } \\
\text { toward a self-directed support approach }\end{array}$ \\
\hline $\begin{array}{l}\text { Greater satisfaction with the availability of quality } \\
\text { services }\end{array}$ & $\begin{array}{l}\text { Providing additional support and information for } \\
\text { family caregivers who may be making decisions on } \\
\text { behalf of a family member }\end{array}$ \\
\hline Greater progress towards personal goals & $\begin{array}{l}\text { Caregivers feeling increasingly isolated over time if } \\
\text { adequate supports are not put in place }\end{array}$ \\
\hline $\begin{array}{l}\text { More likely to feel that needs are being met and less } \\
\text { unmet needs }\end{array}$ & $\begin{array}{l}\text { Family caregivers may be emotionally and practically } \\
\text { underprepared for the task of organising support } \\
\text { services }\end{array}$ \\
\hline $\begin{array}{l}\text { Better response to cultural needs through greater } \\
\text { flexibility, choice and control over support workers }\end{array}$ & Finding and hiring workers \\
\hline $\begin{array}{l}\text { Increased hours of support, stability and satisfaction } \\
\text { through flexible hiring of family and friends }\end{array}$ & Conflict of interest in hiring family members \\
\hline $\begin{array}{l}\text { The support provided is the same quality as support } \\
\text { provided under agency-directed models }\end{array}$ & Question about cost effectiveness \\
\hline \multicolumn{2}{|l|}{ More positive health outcomes } \\
\hline Spend less than their allocated allowance & \\
\hline
\end{tabular}




\section{Challenges of self-directed support}

A number of challenges and issues with self-directed models of support have also been identified in the literature. In particular, there is concern that some consumers may not have the capacity to manage their funds, resulting in inappropriate use of their allowance or inadequate services being received (Adams \& Drake 2006; Adelman et al. 2012; Alakeson 2008; 2010). Some strategies that have been employed to manage this issue are: excluding those persons deemed unable or unsuitable to manage their own budgets (Duffy 2007a); consumers to undergo skills assessment and agree to training in skills relevant to managing their own services (Ministry of Health 2003); and restricting a portion of the budget to 'traditional services' to ensure that important services are being received (Cook et al. 2008). Another approach is to enable consumers to nominate a representative surrogate decisionmaker or nominee decisionmaker to assist them in the decision-making process, or to make decisions on their behalf (Duffy 2007a; Kodner 2003; Shen, Smyer, Mahoney, Simon-Rusinowitz et al. 2008). In particular, this was found to be a suitable option for those with cognitive and developmental disabilities who experienced difficulty in managing their budgets independently, as they were still able to benefit from expressing their personal preferences in relation to their support and the flexibility that self-direction allows (Mahoney et al. 2007).

Consumer interest in self-directed support is also an important aspect to consider. Research has demonstrated that consumers and caregivers vary in terms of their interest in managing the support received (Alakeson 2007; Duffy 2007a; Mahoney, Simon-Rusinowitz, Loughlin et al. 2004; Olinzock 2004; Putnam et al. 2010; Sciegaj et al. 2004) and that over time, people may change their mind regarding the amount of control they desire (Putnam et al. 2010; The State of Queensland 2012). Self-directed support programs must therefore be able to repond to these differing preferences and changing situations (Duffy 2007a).

Another challenge in implementing self-directed models of support is addressing concerns regarding the potential for intended or unintended exploitation where the level of monitoring of services among agencies is not prescribed (Adelman et al. 2012; Matthias \& Benjamin 2003). Given the involvement of vulnerable populations, it is important to consider how models of self-directed support can appropriately balance the desire for greater control and self-management whilst ensuring safeguards against abuse can be put into place (Fyson 2009). However, research has indicated that reports of financial and physical abuse in self-directed support programs are rare (Alakeson 2010; Low et al. 2012; Young $\&$ Sikma 2003) and that reports of physical abuse and neglect were no more likely in self-directed support compared to agency-direct support (Matthias \& Benjamin 2003).

The transition from agency-directed support to self-directed support could be challenging for some service providers and professionals, as the changes may require some changes to philosophies and roles (Adams \& Drake 2006; Doty 
et al. 2010; Duffy 2007a). Many professionals report concerns over how to find the correct balance between empowering consumers by giving them more control whilst also meeting their duty of care and responsibility to ensure that consumers are receiving suitable, adequate support (Department of Health and Ageing 2012, Fox \& Kim 2004; Young \& Sikma 2003). The evaluation of the Australian self-directed aged care packages identified the need for more guidance and support to be provided by government departments to service providers during the implementation of self-directed support packages and the establishment of new practices to address this issue (Department of Health and Ageing 2012). Training for providers on how best to encourage and assist consumers to take on a larger role in directing their services has also been identified as important (Davis et al. 2005; Deparment of Health and Ageing 2012; Glendinning et al. 2008). However, as Lord and Hutchinson (2003) concluded in their review of international individualised support and funding programs, when there is a shift in disability practice that facilitates capacity building, individuals, families and communities are enabled to develop a sense of control and participation.

Additional support and information has also been identified as an important issue for family caregivers who may be making decisions on behalf of a family member (Putnam et al. 2010). In one program (see Foster et al. 2005), caregivers who had a family member enrolled in a US self-directed support program reported less physical, emotional and financial strain than caregivers involved in traditional agency-directed support. This may be due to the use of allowances to employ a worker to reduce their workload, thereby reducing some of the pressure felt by caregivers. However, research has also demonstrated that caregivers involved in self-directed support programs may feel increasingly isolated as time progresses if adequate supports are not implemented (Ottmann et al. 2009). Research has found that family caregivers may be emotionally and practically underprepared for the task of organising support services and that feeling prepared predicted higher levels of satisfaction with caregiving work (Kietzman et al. 2008). Therefore, adequate preparation and support for caregivers over a longer period of time appears to be important for ensuring satisfaction and continued involvement in self-directed models of support.

Challenges in self-directed support also exist in terms of finding and hiring workers. Research conducted in the United States on self-directed programs suggests that employing workers can be a key challenge for many participants, given the shortage of available workers who are willing to take on such a role, especially in programs which do not allow consumers to hire family members (Doty et al. 2010; Grossman et al. 2007; Low et al. 2012; Young \& Sikma 2003). The hiring of family members, particularly immediate family, remains a controversial issue as there are concerns that it creates the potential for a conflict of interest or may increase the likelihood of abuse against more vulnerable consumers (Barczyk \& Lincove 2010). However, in addition to the convenience of being able to hire family as paid carers, studies have shown that there are 
benefits to health and quality of life (Barczyk \& Lincove 2010). Consumers who hired family members reported experiencing greater stability of support, greater satisfaction in their relationship with their carer, and reduced feelings of risk compared to those who hired friends or had no previous relationship with the employee (Matthias \& Benjamin 2008). Many consumers also believe that they should be able to hire family members, including parents and spouses (Grossman et al. 2007) and cite the ability to pay a family member as a key reason for being interested in a self-directed model of support (Mahoney et al. 2004). Australian programs have so far discouraged consumers from hiring family members and the impact of this policy is not yet known (Low et al. 2012).

Interest also surrounds the issue of how cost-effective self-directed programs would be and how they would compare to the cost of agency-directed services. Initial concern that participants may overspend their budgets has been alleviated by results of pilot programs showing that many consumers spend less than their allocated allowance (Alakeson 2007; Barczyk \& Lincove 2010; Cook et al. 2008). It is also suggested that allowing consumers to choose and control their own support will be cost effective as they are in the best position to know their own values, preferences and goals, thereby reducing the chance that unsuitable services or supports will be purchased (Adams \& Drake 2006; Duffy 2007b). Results of financial comparisons between the models of support tend to find that self-directed services are more expensive than agency-directed services (Alakeson 2010; Barrczyk \& Lincove 2010). This was partly attributed to the fact that individuals involved in self-directed programs received the full amount of personal care that they were entitled to, whereas consumers receiving agency-directed support did not (Alakeson 2010). However, this increase in spending on personal care assistance resulted in other economic benefits, with long-term analysis indicating a subsequent reduction in nursing home use (Alakeson 2010). It is also worth considering that the private health insurance sector in the United States has commenced the use of Consumer Directed Health Care Plans (CDHCP). A tentative conclusion that can be drawn from this spreading movement into the private sector is that it appears more cost effective and efficient for individuals to control how their money is spent, although further research is needed to confirm this. The earlier table provides a summary of the challenges and benefits associated with self-direction movements across the industrialised world.

\section{Recommendations}

Within the Australian context, most state jurisdictions are moving towards or have been implementing self-direction for some time, perhaps as the next logical step to realising and actualising person-centred support and planning (Crozier \& Muenchberger 2013). The introduction of a National Disability Insurance Scheme has possibly prompted an escalation in the momentum of this movement. The key challenge for a nation implementing self-direction is defining how much self-direction is valuable and meaningful to the consumer, 
and determining the areas of care and support where it could best apply. Where some jurisdictions talk about a continuum of support (for example, The State of Queensland 2012), determining where an individual is positioned on this continuum may be more complex. A key insight that emerged from the selected literature is that satisfaction in service delivery and life domains is generally higher where control or self-direction is maximised (for example, Barczyk \& Lincove 2010; Lachapelle et al. 2005; Mahoney et al. 2002; Mahoney et al. 2004; McDougall et al. 2010; Wehmeyer \& Schwartz 1998). This finding suggests that supporting people to develop the necessary skills to undertake self-direction is a positive and necessary step forward. Developed from our direct work in the disability field and the insights from the literature presented here, we offer the following self-direction decision tree. This decision tree is intended for use at system and organisational policy decisionmaking levels. The decision tree may help to guide the complex and difficult decisions that are required in the design of self-directed packages (see Figure 1).

\section{Acknowledgements}

Endeavour Foundation Endowment Challenge Fund and the Centre of National Research on Disability and Rehabilitation Medicine. 
Figure 1. Self-direction policy decision tree

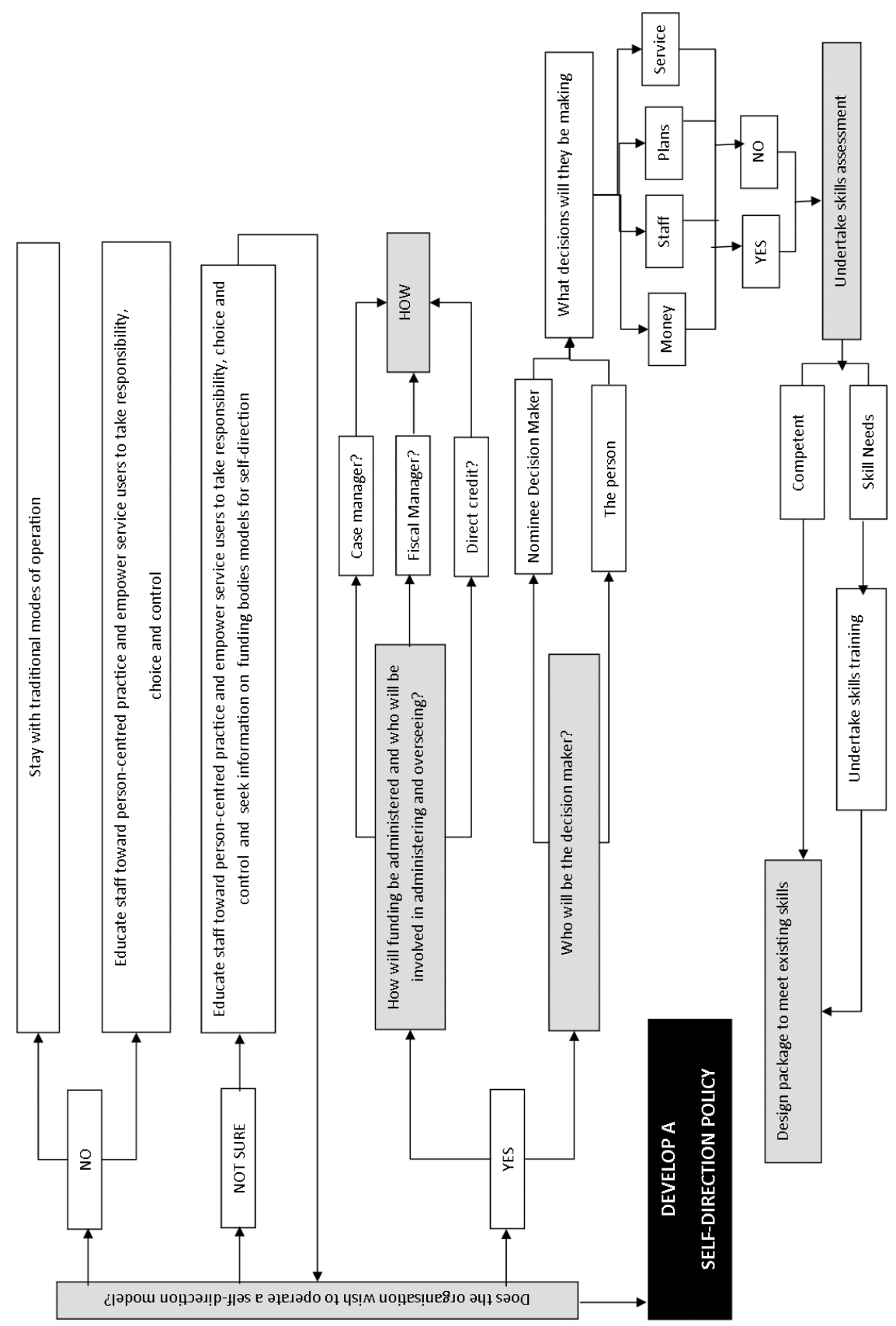




\section{References}

Adams, J.R. \& Drake, R.E. (2006) 'Shared decision-making and evidencebased practice', Community Mental Health Journal, 42 (1), 87-105. doi: 10.1007/s10597-005-9005-8

Adelman, T., Kitchener, M., Ng, T. \& Harrington, C. (2012) 'Change and inertia in the New York State medicaid personal care services program: an institutional case study', Journal of Aging \& Social Policy, 24 (3), 309327. doi:10.1080/08959420.2012.683319

Alakeson, V. (2007) 'Direct dollars', Mental Health Today, 16-18.

— (2008) 'Self-directed care for adults with serious mental illness: the barriers to progress', Psychiatric Services, 59 (7), 792-794.

- (2010) 'International development in self-directed care', Issue Brief, 78, $1-11$.

Barczyk, A.N. \& Lincove, J.A. (2010) 'Cash and counseling: a model for self-directed care programs to empower individuals with serious mental illnesses', Social Work in Mental Health, 8 (3), 209-224. doi: 10.1080/15332980903405298

Carlson, B.L., Foster, L., Dale, S.B. \& Brown, R. (2007) 'Effects of cash and counseling on personal care and well-being', Health Services Research, 42 (1 Pt 2), 467-487. doi: 10.1111/j.1475-6773.2006.00673.x

Clapton, J. \& Fitzgerald, J. (1997) 'The history of disability: a history of otherness', New Renaissance Magazine, 7 (1), 1-3.

Cook, J.A., Russell, C., Grey, D.D. \& Jonikas, J.A. (2008) 'Economic grand rounds. A self-directed care model for mental health recovery', Psychiatric Services, 59 (6), 600-602.

Cook, J.A., Shore, S.E., Burke-Miller, J.K., Jonikas, J.A., Ferrara, M., Colegrove, S., Norris, W.T., Ruckdeschel, B., Batteiger, A.P., Ohrtman, M., Grey, D.D. \& Hicks, M.E. (2010) 'Participatory action research to establish self-directed care for mental health', Psychiatric Rehabilitation Journal, 34 (2), 137-144.

Crozier, M., \& Muenchberger, H. (2013). “"It's your problem, not mine”: does competence have anything to do with desire and aspiration to self-direct?' Australian Health Review, e-pub October 11, doi:10.1071/AH13053

Davis, C.B., Cornman, C.B., Lane M.J. \& Patton, M. (2005) 'Person-centered planning training for consumer-directed care for the elderly and disabled', Care Management Journals, 6 (3), 122-130.

de Miranda, J. (2004) 'Coming to the addiction community: consumer-directed care', Behavioral Healthcare Tomorrow, 13 (3), 25.

Deparment of Health and Ageing (2012) Evaluation of the Consumer-Directed Care Initiative - Appendices, http://www.health.gov.au/internet/main/ publishing.nsf/Content/659479336D383B53CA25784F0011 4B0E/\$File/CDC-Eval-Final-Rep-App.pdf 
Doty, P., Mahoney, K.J. \& Sciegaj, M. (2010) 'New state strategies to meet long-term care needs', Health Affairs, 29 (1), 49-56. doi: 10.1377/ hlthaff.2009.0521

Duffy, S. (2007a) 'Care management and self-directed support', Journal of Integrated Care, 15 (5), 3-14.

- (2007b) 'The economics of self-directed support', Journal of Integrated Care, 15 (2), 26-37.

Foster, L., Brown, R., Phillips, B. \& Carlson, B.L. (2005) 'Easing the burden of caregiving: the impact of consumer direction on primary informal caregivers in Arkansaw', Gerontologist, 45 (4), 474-485. doi: 10.1093/ geront $/ 45.4 .474$

Fox, M.H. \& Kim, K.M. (2004) 'Evaluating a Medicaid home and communitybased physical disability waiver', Family \& Community Health, 27 (1), $37-51$.

Fyson, R. (2009) 'Independence and learning disabilities: why we must also recognize vulnerability', Journal of Adult Protection, 11 (3), 18-25.

Glendinning, C., Challis, D., Fernández, J.L., Jacobs, S., Jones, K., Knapp, M., Manthorpe, J., Moran, N., Netten, A., Stevens, M. \& Wilberforce, M. (2008) Evaluation of the individual budgets pilot programme: final report, http://www.york.ac.uk/inst/spru/pubs/pdf/IBSEN.pdf

Gloag, D. (1985) 'Severe disability: 2 - Residential care and living in the community', British Medical Journal, 290 (6465), 368-372. doi:10.1136/ bmj.290.6465.368

Gray, D.B., Dashner, J.L., Morgan, K.A., Lyles, M., Scheller, M., Morris, C.L. \& Hollingsworth, H.H. (2009) 'Influence of a consumer-directed personal assistance services program on the lives of persons with mobility impairments', Disability and Health Journal, 2 (4), 188-195. doi: 10.1016/j.dhjo.2009.05.002

Grossman, B.R., Kitchener, M., Mullan, J.T. \& Harrington, C. (2007) 'Paid personal assistance services: an exploratory study of working-age consumers' perspectives', Journal of Aging \& Social Policy, 19 (3), 27-45. doi: 10.1300/J031v19n03_03

Kietzman, K.G., Benjamin, A.E. \& Matthias, R.E. (2008) 'Of family, friends, and strangers: caregiving satisfaction across three types of paid caregivers', Home Health Care Services Quarterly, 27 (2), 100-120.

Kim, K.M., White, G.W. \& Fox, M.H. (2006) 'Comparing outcomes of persons choosing consumer-directed or agency-directed personal assistance services', Journal of Rehabilitation, 72 (2), 32-43.

Kodner, D.L. (2003) 'Consumer-directed services: lessons and implications for integrated systems of care', International Journal of Integrated Care, 3 (2), 17. 
Lachapelle, Y., Wehmeyer, M., Haelewyck, M.C., Courbois, Y., Keith, K., Schalock, R., Verdugo, M.A. \& Walsh, P.N. (2005) 'The relationship between quality of life and self determination: an international study', Journal of Intellectual Disability Research, 49 (10), 740-744.

Lombe, M., Mahoney, K. \& Bekteshi, V. (2009) 'Exploring patterns of service utilization among persons with disabilities in a consumer-directed care program', Journal of Social Work in Disability Rehabilitation, 8 (1), 2136. doi: 10.1080/15367100802665524

Lord, J. \& Hutchinson, P. (2003) 'Indivdiualised support and funding: building blocks for capacity building and inclusion', Disability and Society, 18 (1), 71-86. doi: dx.doi.org/10.1080/713662196

Loughlin, D.M., Simon-Rusinowitz, L., Mahoney, K.J., Desmond, S.M., Squillace, M.R. \& Powers, L.E. (2004) 'Preferences for a cash option versus traditional services for Florida children and adolescents with developmental disabilities', Journal of Disability Policy Studies, 14 (4), 229-240. doi: 10.1177/104420730 40140040501

Low, L.F., Chilko, N., Gresham, M., Barter, S. \& Brodaty, H. (2012) 'An update on the pilot trial of consumer-directed care for older persons in Australia', Australasian Journal on Ageing, 31 (1), 47-51. doi: 10.1111/ j.1741-6612.2011.00572.x

Mahoney, K.J., Desmond, S.M., Simon-Rusinowitz, L., Loughlin, D.M. \& Squillace, M.R. (2002) 'Consumer preferences for a cash option versus traditional services: telephone survey results from New Jersey elders and adults', Journal of Disability Policy Studies, 13 (2), 74-86.

Mahoney, K.J., Fishman, N.W., Doty, P. \& Squillace, M.R. (2007) 'The future of cash and counseling: the framers' view', Health Services Research, 42 (1 Pt 2), 550-566.

Mahoney, K.J., Simon-Rusinowitz, L., Loughlin, D.M., Desmond, S.M. \& Squillace, M.R. (2004) 'Determining personal care consumers' preferences for a consumer-directed cash and counseling option: survey results from Arkansas, Florida, New Jersey, and New York elders and adults with physical disabilities', Health Services Research, 39 (3), 643-663. doi: 10.1111/j.1475-6773.2004.00249.x

Matthias, R.E. \& Benjamin, A.E. (2003) 'Abuse and neglect of clients in agency-based and consumer-directed home care', Health \& Social Work, 28 (3), 174-184.

_ (2008) 'Paying friends, family members, or strangers to be home-based personal assistants: how satisfied are consumers?' Journal of Disability Policy Studies, 18 (4), 205-218. doi: 10.1177/1044207307311526

McDougall, J., Evans, J. \& Baldwin, P. (2010) 'The importance of selfdetermination to perceived quality of life for youth and young adults with chronic conditions and disabilities', Remedial and Special Education, 31 (4), 252-260. 
Ministry of Health (2003) Individualised Funding: Guidance and Good Practice. Wellington: Ministry of Health.

New South Wales Government (2010) Stronger Together: A New Direction for Disability Services in NSW 2006-2016, http://www.adhc.nsw.gov.au/_ data/assets/file/0004/227866/StrongerTogetherPlan_2.pdf

Olinzock, B.J. (2004) 'A model for assessing learning readiness for self-direction of care in individuals with spinal cord injuries: a qualitative study', SCI Nursing, 21 (2), 69-74.

Ottmann, G.F. \& Laragy, C. (2010) 'Developing consumer-directed care for people with a disability: 10 lessons for user participation in health and community care policy and program development', Australian Health Review, 34 (4), 390-394. doi: 10.1071/AH09759

Ottmann, G., Laragy, C. \& Haddon, M. (2009) 'Experiences of disability consumer-directed care users in Australia: results from a longitudinal qualitative study', Health o Social Care in the Community, 17 (5), 466475. doi: 10.1111/j.1365-2524.2009.00851.x

Productivity Commission (2011) Productivity Commission Inquiry Report: Disability Care and Support, Canberra: Australian Government.

Putnam, M., Pickard, J.G., Rodriguez, C. \& Shear, E. (2010) 'Stakeholder perspectives on policies to support family caregviers of older adults with dementia', Journal of Family Social Work, 13 (2), 173-190. doi: 10.1080/10522150903487479

Scherzer, T., Wong, A. \& Newcomer, R. (2007) 'Financial management services in consumer-directed programs', Home Health Care Services Quarterly, 26 (1), 29-42. doi: 10.1300/J027v26n01_03

Sciegaj, M., Capitman, J.A. \& Kyriacou, C.K. (2004) 'Consumer-directed community care: race/ethnicity and individual differences for control', Gerontologist, 44 (4), 489-499. doi: 10.1093/geront/44.4.489

Shen, C., Smyer, M.A., Mahoney, K.J., Loughlin, D.M., Simon-Rusinowitz, L. \& Mahoney, E.K. (2008) 'Does mental illness affect consumer direction of community-based care? Lessons from the Arkansaw cash and counseling program', Gerontologist, 48 (1), 93-104. doi: 10.1093/geront/48.1.93

Shen, C., Smyer, M., Mahoney, K.J., Simon-Rusinowitz, L., Shinogle, J., Norstrand, J., Mahoney, E., Schauer, C. \& del Vecchio, P. (2008) 'Consumer-directed care for beneficiaries with mental illness: lessons from New Jersey's Cash and Counseling program', Psychiatric Services, 59 (11), 1299-1306.

The State of Queensland. (2012) Your Life Your Choice: Self-Directed Support Framework, http://www.communities.qld.gov.au/resources/disability/keyprojects/your-life-your-choice/ylyc-self-directed-support-framework.pdf

Wehmeyer, M.L. \& Schwartz, M. (1998) 'The self determination focus of transition goals for students with mental retardation', Career Development for Exceptional Individuals, 21 (1), 75-86. 
Young, H.M. \& Sikma, S.K. (2003) 'Self-directed care: an evaluation', Policy, Politics \& Nursing Practice, 4 (3), 185-195. 